\title{
Public Procurement, Big Data Analytics Capabilities, and Healthcare Supply Chain Sustainability
}

\author{
Md Ahsan Uddin Murad \\ University of Technology Sydney \\ 13449222@student.uts.edu.au
}

\author{
Dilek Cetindamar Kozanoglu \\ University of Technology Sydney
}

Dilek.CetindamarKozanoglu@uts.edu.au

\author{
Subrata Chakraborty \\ University of Technology Sydney \\ Subrata.Chakraborty@uts.edu.au
}

\begin{abstract}
Big data analytics (BDA) is considered the most critical supply chain activity for organizations. Implementing BDA requires specialized infrastructure coupled with specialized analytical expertise. Most of the existing research focuses on building BDA capabilities or perceived benefits of organizations' BDA capabilities. However, the benefits of having BDA capabilities, neither immediately visible nor straightforward. Optimizing procurement is one of the many intermediate factors that influence $B D A$ capabilities' impact on the supply chain's sustainability performance. This paper has analyzed the existing literature to develop a conceptual framework to investigate the relationships among procurement optimization, $B D A$ capabilities, and healthcare sustainable supply chain.
\end{abstract}

Keywords: Big Data Analytics Capability (BDAC), Optimization, Public Procurement, Sustainability, Supply Chain

\section{Introduction}

Companies invest in Big Data Analytics (BDA) to overcome complexity in managing bid data and leverage competitive advantage in their supply chain functions [1]. BDA involves both technologies and organizational capabilities. BDA capabilities are widely accepted skill sets to transform how firms usually do business [2]. It is the competence of a firm to provide business insights by capturing and analyzing big data. In doing so, BDA capabilities holistically utilize a firm's data, technology and talent as an organization-wide process [2-4]. This paper proposes a framework to study the relationship among BDA capabilities, procurement optimization, and the supply chain's (SC) sustainability performance.

BDA capabilities become instrumental in all procurement activities with many innovation potentials. For example, in the future big dataenabled procurement analytics will not just understand current spending but also will provide optimal solution-oriented insights through generating visual maps based on procurement results [5]. BDA can stimulate inter-organizational learning and analysis of procurement and delivery patterns, leading to greater optimization of assets distribution and use of assets[6]. Thus it will minimize both spending and the consumption of resources towards sustainable sourcing.

Understanding the role of BDA in enhancing the healthcare SC's sustainability performance is a relevant priority for a few reasons. Firstly, the power of handling big data has enormous potential to make the firm [7] and SC [8] more successful. Secondly, research in many sectors found that BDA capability enhances the SC's sustainable performance in three dimensions: Economic, Social and Environmental [7, 9]. Thirdly, sustainability is now considered a significant requirement to overcome the growing challenges in coping with the current healthcare needs and obtaining strategic fit for the future [10]. The quality of healthcare depends on social and environmental factors of health services. Good healthcare must consider the environmental and social consequences of achieving economies of scale in healthcare output [11]. A sustainable healthcare system can better manage extensive healthcare data to achieve maximum healthcare output [10]. Ensuring a sustainable SC in developing countries' healthcare can facilitate quality healthcare at an affordable cost. However, research focus on public healthcare context, more precisely procurement component of a public healthcare SC is still niche. Public sector procurement is very complex and involves substantial uncertainty [12]. The situation in a developing country context is even harder due to the lack of transparent governance. Existing BDA research is highly concentrated on building the BDA capabilities only [13]. It is well accepted that having a solid BDA strategy and practice is critical for the business decision process; however, mere 
BDA practice is insufficient for sustainable organizational success. Studies revealed that BDA would continue to be widely adopted but post BDA success will diminish over time, and data management challenges will be overwhelmingly challenging and costly [4]. Since the early days of the digitization issue coined, it is emphasized that implementation activity is highly interconnected [14]. Thus requires streamlined coordination and just-in-time nature availability of all interdependent or mediating actors.

This article argues that BDAC is necessary for successful BDA implementation; however, other intermediate factors' mediating factors may also have the driving role in organizational performance from the BDA implementation. Thus, this article develops a conceptual framework to shed light on public procurement optimization's mediating role between BDAC and healthcare SC sustainability. We bring together three different research streams related to BDAC, procurement optimization, and the SC's sustainability performance. Each of the three research areas is important in the respective discipline; however, integrating three areas could provide a comprehensive lens to understand how BDA implementation in the SC could enhance SCs' sustainability. After an extensive literature survey, we are convinced that no such attempts have been taken to study the proposed issue, as discussed in section 2. Section 3 represents a framework for further research in integrating BDAC, procurement optimization, and supply chain sustainability performance. This sections also discuss the different constructs of the proposed framework. The paper ends with a few suggestions for future studies

\section{Literature Review}

We conducted our literature review by searching SCOPUS, Web of Science (WoS), and Google Scholars (GS) databases. A pilot search of journal articles was conducted on 11 October 2020 and later updated on 19 August 2021. The overall search criteria and findings are presented in the following two tables.

Table 1: Search criteria and outcome

\begin{tabular}{|c|c|c|c|}
\hline Features & BDAC & $\begin{array}{l}\text { Procurement } \\
\text { Optimization }\end{array}$ & Supply Chain Sustainability \\
\hline $\begin{array}{l}\text { Research } \\
\text { Question }\end{array}$ & $\begin{array}{l}\text { Does BDAC improve } \\
\text { healthcare supply chain } \\
\text { sustainability? }\end{array}$ & $\begin{array}{l}\text { Does procurement } \\
\text { optimization have a } \\
\text { mediating role between } \\
\text { BDAC and healthcare } \\
\text { sustainable supply chain? }\end{array}$ & $\begin{array}{l}\text { Does BDAC improve } \\
\text { healthcare supply chain } \\
\text { sustainability? }\end{array}$ \\
\hline $\begin{array}{l}\text { Search } \\
\text { criteria }\end{array}$ & $\begin{array}{l}\text { ( ALL ( healthcare OR } \\
\text { "health care" ) AND } \\
\text { PUBYEAR > 2009) AND ( } \\
\text { ( ( ( bda OR bdac ) ) AND ( } \\
\text { "big data" ) ) AND ( "supply } \\
\text { chain" ) ) AND ( } \\
\text { sustainability OR sustainable } \\
\text { ) AND ( LIMIT-TO ( } \\
\text { DOCTYPE, "ar" ) ) AND ( } \\
\text { LIMIT-TO ( LANGUAGE, } \\
\text { "English" ) ) }\end{array}$ & $\begin{array}{l}\text { ( ALL ( procurement ) } \\
\text { AND PUBYEAR > } \\
\text { 2009 ) AND ( ( ( bda } \\
\text { OR bdac ) ) AND ( "big } \\
\text { data" ) ) AND ( } \\
\text { healthcare OR "health } \\
\text { care" ) AND ( LIMIT- } \\
\text { TO ( DOCTYPE, "ar" ) ) } \\
\text { AND ( LIMIT-TO ( } \\
\text { LANGUAGE, "English" } \\
\text { )) }\end{array}$ & $\begin{array}{l}\text { ( ALL ( healthcare OR } \\
\text { "health care" ) AND } \\
\text { PUBYEAR > 2009) AND ( } \\
\text { ( ( ( bda OR bdac ) ) AND ( } \\
\text { "big data" ) ) AND ( "supply } \\
\text { chain" ) ) AND ( } \\
\text { sustainability OR sustainable } \\
\text { ) AND ( LIMIT-TO ( } \\
\text { DOCTYPE, "ar" ) ) AND ( } \\
\text { LIMIT-TO ( LANGUAGE, } \\
\text { "English" ) ) }\end{array}$ \\
\hline $\begin{array}{l}\text { Article } \\
\text { retrieved }\end{array}$ & $\begin{array}{l}\text { Scopus (96), WoS (89), GS } \\
\text { (99) }\end{array}$ & $\begin{array}{l}\text { Scopus (20), WoS(18), GS } \\
(21)\end{array}$ & $\begin{array}{l}\text { Scopus (96), WoS (89), GS } \\
(99)\end{array}$ \\
\hline \multirow{2}{*}{$\begin{array}{l}\text { First } \\
\text { screening }\end{array}$} & $101 *$ & $22 *$ & $101 *$ \\
\hline & \multicolumn{3}{|c|}{ *total article after removing duplication and initial screening by reading title only } \\
\hline \multirow{2}{*}{$\begin{array}{l}\text { Second } \\
\text { screening }\end{array}$} & $56 * *$ & $4 * *$ & $56 * *$ \\
\hline & \multicolumn{3}{|l|}{ **after abstract analysis } \\
\hline \multirow{2}{*}{$\begin{array}{l}\text { Final } \\
\text { screening }\end{array}$} & \multicolumn{3}{|c|}{$43 * * *$} \\
\hline & \multicolumn{3}{|c|}{$\begin{array}{l}\text { ***After full-text analysis, considering all three research contexts together and BDAC as } \\
\text { input and any of our concepts (healthcare/health, sustainability and procurement) is discussed } \\
\text { either as output or as mediating or moderator variable. }\end{array}$} \\
\hline
\end{tabular}


Efforts were given to find out the most quality work in BDAC, procurement and sustainability. BDAC terminology was mainly coined in 2000 . After the search process generated a bibliography of candidate studies, some studies were eliminated at the very outset if they fit in one or more exclusion criteria. The remaining papers were thoroughly studied for further inclusion or exclusions. Some papers were excluded at this stage because they did not have sufficient statistics to identify impact and contributions, even though they met all inclusion criteria. A quality rubric introduced by [15] is used to evaluate each article's quality. The rubric examines research articles on seven criteria, including Objectives, Literature review, Theoretical framework, Study participants, methodology used, Results and discussion, and Significance of the study. Each quality rubric component was measured on a scale of zero to three, where $0=$ Below standard, $1=$ Near to standard, 2= Standard, and 3= Exceeds standard (Detailed criteria are skipped due to page limit). Articles overall scores of more than nine [15] are shortlisted for further review. Articles scored below, or equal to nine, are considered "Poor" and "Inadequate" articles and were excluded. A total of 43 research studies are finalized for further analysis and review.

In the first step of the analysis, articles were categorized into the year of publication, country, theory adopted, source Journal etc. Descriptive analytics were generated to visualize the current trend in the extant literature of BDAC, procurement optimization and healthcare SC sustainability. The findings of the first step analysis are skipped intentionally to keep the articles succinct. In the second stage of analysis, all 43 articles were synthesized more deeply to find the input for the three research questions of our proposed research. In this stage, all articles are synthesized on input metric, output metric, theory adoption, mediation/moderator metric and context of the study areas. The findings generate a pictorial demonstration of current research and gaps where future studies could contribute. Table 2 presents the findings of one of such analyses in the second stage.

Table 2: List of studies with BDAC as input and Sustainability as Output

\begin{tabular}{|l|l|}
\hline BADC as input & Mediator or Moderator \\
\hline$[9,16-24]$ & Innovation Capability, Data \\
{$[[25]$ BDA-AI] } & Availability[20], GM Practice, LSS \\
& Effort[22], Innovative Green Product \\
& Development, Employee \\
& Development, Innovation and \\
& learning performance, SC \\
& Innovativeness [23], SC Complexity \\
& [9], Green digital learning orientation \\
& [25], Circular economy practice [24], \\
& Sustainable SC flexibility[24] \\
\hline
\end{tabular}

Among the final 43 articles, researchers have paid more interest in BDA, primarily in manufacturing (15 articles) and retail (10 articles); few studies shed light on the service second. Some studies (7 articles) included healthcare as a study area together with other sectors. Only one article emphasized the role of BDAC in developing an integrated hospital $\mathrm{SC}$; it remains the only article that exclusively investigated any issue related to healthcare where BDAC is an input [26]. Due to the lean characteristics in structure, the SC of many sectors was hard hit by COVID -19 and put the resilience of SCs to test [27]. Managing hospital SC more flexibly in current economic uncertainty and market volatility has become more critical; however, it received very little attention in healthcare literature [26]. So, it is beyond question that technology will be a driving force in reshaping healthcare SC to align with the COVID outbreak.
Sustainability as output

Sustainable Innovativeness[16], Success of

Sustainability Development Project [17], SC

Sustainability [18], Sustainability-Air pollution

Management [19], Sustainable Competitive

Advantage [20], Sustainability of Innovation and Organizational Development [21],

Environmental Performant [22], Sustainable SC Performance ([23];[24]), Sustainable Supply Chain Performance [9], Green Supply chain and hospital environment performance [25]

Empirically validated that BDA improves SC performance in highly challenging environments [28]. Considering the proven success of BDA in other sectors, we find the first gap in the literature: the implementation of BDA in the health sector.

Our literature search outcome shows that most studies (at least $72 \%$ ) are conducted in advanced countries, and none of the studies addressed the public procurement issue. BDA implementation barriers are varied to country context [29] and sectors [28]. Here the second gap in the literature we identified is to expand the BDA research in procurement optimization and healthcare into developing countries. Sustainability is considered a significant requirement to overcome the growing challenges in coping with the current healthcare needs and obtaining strategic fit for the future [10]. Existing healthcare sustainability research mainly focused on recycling waste to reduce greenhouse 
gas emissions and pollution through low consumption of new raw materials [30]. However, good healthcare must consider the environmental and social consequences of achieving economies of scale in healthcare output [11]. We observe the third literature gap, a need for a framework to understand the relationship between BDAC and sustainable SC management.

Existing research espouses the future BDA abilities in reducing uncertainties in the $\mathrm{SC}$ through accurate predictions and thus increase sustainable performance [31]. However, sustainability is a relatively new practice in developing countries, let alone understating BDAC to achieve sustainability. Even in developed countries, many organizations have a limited understanding of BDAC [32]. Therefore, whereas successful BDA integration in the $\mathrm{SC}$ requires organizations first to enhance their $\mathrm{BDAC}$, it also requires organization wise support to shift the power to acquire BDAC [33]. Hence, a separate study on low resource country context is required for a more accurate outcome of the role of BDA in the healthcare sustainable SC with a possible intermediate action of public procurement optimization. This paper aims to bridge the identified gaps mentioned above. The next section presents a framework to explore the role of BDAC in the public healthcare procurement optimization that could enhance SC sustainability performance.

\section{Research Framework}

By drawing on prior BDAC studies, we propose a framework as depicted in Figure 1. A similar framework is already tested by researchers with the combination of different output and mediator/moderator, keeping the BDAC as input. For example, sustainable competitive advantage as output and innovation capability as a mediator [20]; operational flexibility of hospital SC as output [26];

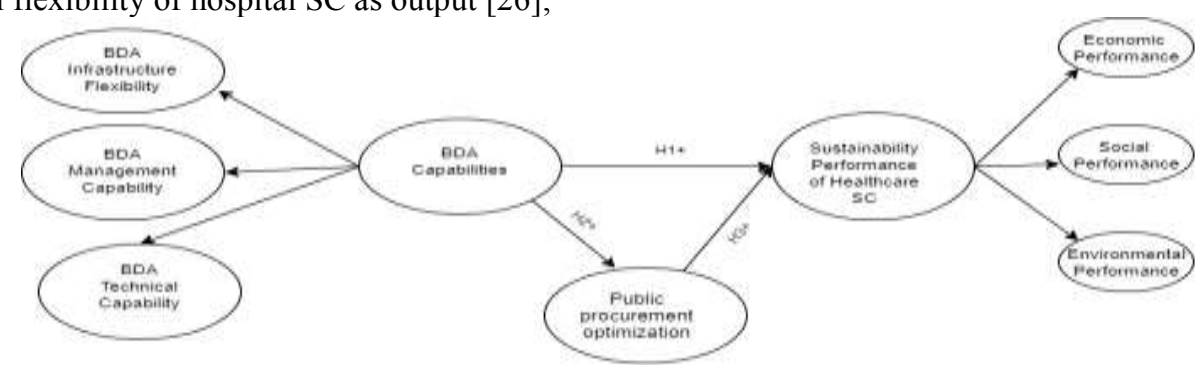

Figure 1. Modified Research Model

In the following paragraphs, we discuss the three key pillars of the framework presented in Figure 1.

\subsection{Big Data Analytics Capability (BDAC)} BDAC is the competence of a firm to provide business insights by capturing and analyzing big data. In doing so, BDAC holistically utilizes a sustainable SC as output [24], and to name a few. Considering those empirical investigations, we argued that the existing empirically tested BDAC models could be extended to validate many other BDA-enabled activities such as procurement optimization, supplier selection, and the healthcare SC sustainability performance. Even though those activities are multi-disciplinary and done asynchronously with potential strategic benefits towards the firm, they require strong alignment across the BDA implementation process. We hypothesize procurement optimization has a mediating role in connection organization BDAC and the sustainable performance of the supply chain. We also postulate BDAC into three subcategories as derived from existing studies. Sustainability performance is posited into three sub-categories.

In contrast to previous BDAC capability findings classified into tangible and intangible categories, we adopted the most supported BDAC composition of three types of capabilities: BDA management capabilities, BDA infrastructure capabilities, and BDA talent capabilities. We suspect that if we consider other components of BDA capabilities mentioned by different prior studies, the empirical result could be slightly different. However, it is neither possible nor realistic to consider BDAC composition exhaustively in one research study. The influence of BDA capabilities on BDA outcomes or consequence of BDA outcomes on the overall organizational outcome is out of our scope. Hence, the research framework presented is deliberately kept parsimonious as it is intended for our qualitative research inquiry on the mediating role of just one construct public procurement optimizing. firm's data, technology and talent as an organization-wide process [3]. A literature survey reveals several approaches to defining and assessing BDAC; therefore, it is conceptualized as a unidimensional construct [34] to comprise a multi-dimensional higher-order construct [2]. Even a combination of mixed approaches is also found. 
For example, [35] used second-order human capability constructs to form other two secondlayer constructs extended up to the third-order to form the first-order construct BDAC eventually. Literature review points out three building blocks for BDA: BDA technology capability, BDA management capability and BDA talent capability [36] [2]. BDA management capability refers to organizational capacity, BDA technical capability refers to the firm's physical infrastructure strength and BDA talent capability refers to the organizational human knowledge capital [3, 4]. Apart from the established three building blocks of BDAC, several investigations theorize two other concepts as intangible characteristics of BDAC, namely 'data-driven culture' and 'intensity of organizational learning [32]. So still, there is no settled theory of measuring BDAC. In our proposed study, the BDAC construct is formed as a combination of three sub-constructs originated from the BDAC model proposed by [3] and followed by $[37,38]$.

\subsection{Public procurement optimization}

An empirical study in the USA and Italy found that BDA adoption in procurement improves the internal procurement performance in terms of optimization of lead time, cost, quality and flexibility [39]. Another empirical study, mainly tested on European and American companies, found artificial intelligence, BDA, and the Internet of Things are three core elements for future procurement automation processes which will create more space for strategic initiatives driven by humans [40]. Another recent empirical study found that advanced technology like BDA influences procurement process optimization [41]. However, in the developing country context, such studies were limited, and traditional legal supervision is only prominent in the procurement process, eventually proven ineffectual. For example, a recent study on Uganda's healthcare revealed that even after a drastic increase in oversight and supervision on public spending, the long term positive result was not achieved [42].

Moreover, the wrongdoer utilizes the latest technologies to shun detection [43, 44]. Recent studies have reported mafia infiltration to prevent more capable and efficient firms from winning the contract [45]. Procuring entities must have technological capabilities to outshine the wrongdoers' ill-willed move to ensure value for money from public money.

However, academic research on procurement analytics is still nascent, and most of the prior studies focused on solution-based on structured data [5]. The same USA based study revealed that currently, there is low usage of advanced procurement analytics, and two major issues preventing the low advances in analytics are data integrity and quality. These findings support our findings that very few studies focused on the developing country contexts where technology adoption is limited. A few research studies focused on developing country contexts which discovered positive impacts of integrating the latest technology in the procurement ecosystem. For example, research on public procurement contracts data of Columbia from 2011 to 2015 suggests an early warning model for early detection of inefficiency and wrongdoings in procurement using technology [45]. The study utilized machine learning modes to predict inefficiencies in public procurement and found net positive impacts. Another study based on Malaysian's public sector health care procurement revealed that the country's public health sector purchased different medicines two to three times the international reference price (IRP) [46]. This study concluded that exiting procurement mechanisms failed to achieve value for money medicine sourcing by balancing ensuring competitive procurement prices and adherence to national procurement policies. Using technology such as BDA can help the concerned authority in dynamic price check to source medicine at IRP. Thus, more research is required on the impact of BDAC on procurement optimization in the developing country context and critical sectorspecific such as healthcare.

\subsection{Sustainability performance of healthcare supply chain}

Some empirical studies indicate BDA's influence on economic, social, and environmental sustainability dimensions; however, those are still fragmented [47]. Some existing literature also discussed the role of BDA in three dimensions of sustainability separately. In terms of the economic dimension of sustainability, BDA increases 15$20 \%$ of Return on Investment (ROI) on supply chain activities [48]. BDA can predict the financial impact to reduce losses, cost reduction [49] and eventually provide a strategic lever to grow revenue [50]. The burning concern of developing nations' healthcare is low ROI and wastage of annual budget allocation. BDA can help health settings maintain optimal inventory, which is crucial for optimal yield from healthcare spending [51]. Some recent studies found a positive effect of BDA in increasing environmental performance. The association between environmental concerns and BDA is relevant and essential to emerging markets such as India and Brazil [16]. BDA can efficiently monitor $\mathrm{CO} 2$ emissions and greenhouse gas emissions [52], helping conduct a more accurate environmental impact assessment necessary for optimum resource utilization [53]. Hence, it facilitates decision-makers to understand 
better environmental impacts in the sustainable supply chain $[52,54]$. Environmental gains through integrating BDA can also bring economic gains through timely demand forecasts to reduce waste and inventory [55]. A time-driven service sector where every resource requires just in time, healthcare can also utilize the power of BDA to save energy and resource. Social sustainably, the third component of the sustainability issue, also positively correlates with disrupting technology such as BDA. A study by [54] espoused a strong potential application of BDA in supply chains' social sustainability aspects. BDA inspires ethical practices among supply chain stakeholders and manages social concerns such as equality, discriminative behaviour, forced labour etc.[55].

\section{Conclusion}

Procurement is one of the most crucial actors of any supply chain. Optimizing procurement has always been a top consideration to maximize supply chain competitiveness. This paper presented a framework to identify the role of BDAC in optimizing public procurement in healthcare and its subsequent contribution to the sustainability of the healthcare SC. The knowledge and the research field addressed by BDAC and SCM community are

\section{Reference}

1. Barrad, S., S. Gagnon, and R. Valverde, An Analytics Architecture for Procurement. International Journal of Information Technologies and Systems Approach, 2020. 13(2): p. 73-98.

2. Akter, S., et al., How to improve firm performance using big data analytics capability and business strategy alignment? International Journal of Production Economics, 2016. 182: p. 113-131.

3. Wamba, S.F., et al., Big data analytics and firm performance: Effects of dynamic capabilities. Journal of Business Research, 2017. 70: p. 356365.

4. Kiron, D., P.K. Prentice, and R.B. Ferguson, $T H E$ ANALYTICS MANDATE, in MITSloan Management Review. 2014, MIT USA.

5. Handfield, R., S. Jeong, and T. Choi, Emerging procurement technology: data analytics and cognitive analytics. International Journal of Physical Distribution \& Logistics Management, 2019. 49(10): p. 972-1002.

6. Chen, P.-T., C.-L. Lin, and W.-N. Wu, Big data management in healthcare: Adoption challenges and implications. International Journal of Information Management, 2020. 53.

7. Dubey, R., et al., Big data analytics and organizational culture as complements to swift trust and collaborative performance in the humanitarian supply chain. International Journal of Production Economics, 2019. 210: p. 120-136. carved out and assessed, and research gaps to address are identified. It is found that the BDAC research has gradually got momentum since 2001; however, it has not covered the public procurement issue in the context of developing countries. Hence, supply chain scholars and practitioners may consider bridging the literature gap by conducting empirical work and increasing our understanding of the relationship between BDAC, procurement optimization and sustainable supply chain. Another stream of research might focus on the benefits of bringing all three sustainably dimensions at the aggregate level. Another interesting theme might be to examine the mediating role between BDAC and sustainable supply chain in different industrial and/or country contexts. Considering the limitations of our proposed study, we put forward two recommendations for future researches: Firstly, more studies are required in developing country contexts to validate our future empirical findings to minimize the generality concern. Secondly, our proposed research study field area, hospitals, are a small part of the healthcare supply chain. More research studies on other healthcare sub-sectors such as pharmaceuticals, medical equipment, eMedicine etc. are required to investigate to strengthen the findings.

8. Govindan, K., et al., Big data analytics and application for logistics and supply chain management. Transportation Research Part E: Logistics and Transportation Review, 2018. 114: p. 343-349.

9. Jeble, S., et al., Impact of big data and predictive analytics capability on supply chain sustainability. The International Journal of Logistics Management, 2018. 29(2): p. 513-538.

10. Karamat, J., et al., Developing Sustainable Healthcare Systems in Developing Countries: Examining the Role of Barriers, Enablers and Drivers on Knowledge Management Adoption. Sustainability, 2019. 11(4).

11. Pencheon, D., Developing a sustainable health care system: the United Kingdom experience. Med J Aust, 2018. 208(7): p. 284-285.

12. Iimi, A., Performance-Based Road Contracts in Zambia. Review of Industrial Organization, 2019. 57(1): p. 107-129.

13. Espinosa, J.A. and F. Armour, The Big Data Analytics Gold Rush: A Research Framework for Coordination and Governance, in 49th Hawaii International Conference on System Sciences. 2016, IEEE: Hawaii USA.

14. Malone, T.W. and K. Crowston, The interdisciplinary study of coordination. ACM Computing Surveys, 1994. 26(1): p. 87-119.

15. Mullet, D.R., A.N. Rinn, and T. Kettler, Catalysts of Women's Talent Development in STEM: A 
Systematic Review. Journal of Advanced Academics, 2017. 28(4): p. 253-289.

16. Song, M., H. Zhang, and J. Heng, Creating Sustainable Innovativeness through Big Data and Big Data Analytics Capability: From the Perspective of the Information Processing Theory. Sustainability, 2020. 12(5).

17. Zhang, H., M. Song, and H. He, Achieving the Success of Sustainability Development Projects through Big Data Analytics and Artificial Intelligence Capability. Sustainability, 2020. 12(3).

18. Shokouhyar, S., M.R. Seddigh, and F. Panahifar, Impact of big data analytics capabilities on supply chain sustainability. World Journal of Science, Technology and Sustainable Development, 2020. 17(1): p. 33-57.

19. Zhang, D., et al., Orchestrating big data analytics capability for sustainability: A study of air pollution management in China. Information \& Management, 2019.

20. Ramadan, M., et al., Sustainable Competitive Advantage Driven by Big Data Analytics and Innovation. Applied Sciences, 2020. 10(19).

21. Hao, S., H. Zhang, and M. Song, Big Data, Big Data Analytics Capability, and Sustainable Innovation Performance. Sustainability, 2019. 11(24).

22. Belhadi, A., et al., The integrated effect of Big Data Analytics, Lean Six Sigma and Green Manufacturing on the environmental performance of manufacturing companies: The case of North Africa. Journal of Cleaner Production, 2020. 252.

23. Bag, S., et al., Big data analytics as an operational excellence approach to enhance sustainable supply chain performance. Resources, Conservation and Recycling, 2020. 153.

24. Edwin Cheng, T.C., et al., Linkages between big data analytics, circular economy, sustainable supply chain flexibility, and sustainable performance in manufacturing firms. International Journal of Production Research, 2021: p. 1-15.

25. Benzidia, S., N. Makaoui, and O. Bentahar, The impact of big data analytics and artificial intelligence on green supply chain process integration and hospital environmental performance. Technological Forecasting and Social Change, 2021. 165.

26. $\mathrm{Yu}, \mathrm{W}$., et al., Role of big data analytics capability in developing integrated hospital supply chains and operational flexibility: An organizational information processing theory perspective. Technological Forecasting and Social Change, 2021. 163.

27. Ivanov, D. and A. Dolgui, Viability of intertwined supply networks: extending the supply chain resilience angles towards survivability. A position paper motivated by COVID-19 outbreak. International Journal of Production Research, 2020. 58(10): p. 2904-2915.
28. Raut, R.D., et al., Big data analytics: Implementation challenges in Indian manufacturing supply chains. Computers in Industry, 2021. 125.

29. Alalawneh, A.A.F. and S.F. Alkhatib, The barriers to big data adoption in developing economies. The Electronic Journal of Information Systems in Developing Countries, 2020. 87(1).

30. Ertz, M. and K. Patrick, The future of sustainable healthcare: Extending product lifecycles. Resources, Conservation and Recycling, 2020. 153.

31. Chong, A.Y.L., et al., Predicting online product sales via online reviews, sentiments, and promotion strategies. International Journal of Operations \& Production Management, 2016. 36(4): p. 358-383.

32. Arunachalam, D., N. Kumar, and J.P. Kawalek, Understanding big data analytics capabilities in supply chain management: Unravelling the issues, challenges and implications for practice. Transportation Research Part E: Logistics and Transportation Review, 2018. 114: p. 416-436.

33. Akhtar, P., et al., Essential Micro-foundations for Contemporary Business Operations: Top Management Tangible Competencies, Relationship-based Business Networks and Environmental Sustainability. British Journal of Management, 2018. 29(1): p. 43-62.

34. Dubey, R., A. Gunasekaran, and S.J. Childe, Big data analytics capability in supply chain agility. Management Decision, 2019. 57(8): p. 2092-2112.

35. Lozada, N., J. Arias-Perez, and G. PerdomoCharry, Big data analytics capability and coinnovation: An empirical study. Heliyon, 2019. 5(10): p. e02541.

36. Yasmin, M., et al., Big data analytics capabilities and firm performance: An integrated MCDM approach. Journal of Business Research, 2020. 114: p. 1-15.

37. Shamim, S., et al., Big data analytics capability and decision making performance in emerging market firms: The role of contractual and relational governance mechanisms. Technological Forecasting and Social Change, 2020. 161.

38. Mikalef, P., et al., The role of information governance in big data analytics driven innovation. Information \& Management, 2020. 57(7).

39. Moretto, A., et al., Increasing the effectiveness of procurement decisions: The value of big data in the procurement process. International Journal of RF Technologies, 2017. 8(3): p. 79-103.

40. Bienhaus, F. and A. Haddud, Procurement 4.0: factors influencing the digitisation of procurement and supply chains. Business Process Management Journal, 2018. 24(4): p. 965-984.

41. Bag, S., et al., Procurement 4.0 and its implications on business process performance in a circular economy. Resources, Conservation and Recycling, 2020. 152. 
42. Peiffer, C., R. Armytage, and H. Marquett, Uganda's Health Sector as a 'Hidden' Positive Outlier in Bribery Reduction, in The Developmental Leadership Program (DLP), U.o. Birmingham, Editor. 2018: UK.

43. Hagan, A.O., Behind Bars: The Truth about Drugs in Prisons. Foresic Research \& Criminology International Journal, 2017. 5(3).

44. Dávid-Barrett, E. and M. Fazekas, Anti-corruption in aid-funded procurement: Is corruption reduced or merely displaced? World Development, 2020. 132.

45. Gallego, J., G. Rivero, and J. Martinez, Preventing rather than punishing: An early warning model of malfeasance in public procurement. Int J Forecast, 2021. 37(1): p. 360-377.

46. Hamzah, N.M., P.N. Perera, and R.P. RannanEliya, How well does Malaysia achieve value for money in public sector purchasing of medicines? Evidence from medicines procurement prices from 2010 to 2014. BMC Health Serv Res, 2020. 20(1): p. 509.

47. Song, M., et al., How would big data support societal development and environmental sustainability? Insights and practices. Journal of Cleaner Production, 2017. 142: p. 489-500.

48. Ahmed, A.K., C.B.S. Kumar, and S. Nallusamy, Study on environmental impact through analysis of big data for sustainable and green supply chain management. International Journal of Mechanical and Production, 2018. 8(1): p. 1245-1254.

49. Roy, M. and A. Roy, Nexus of Internet of Things (IoT) and Big Data: Roadmap for Smart Management Systems (SMgS). IEEE Engineering Management Review, 2019. 47(2): p. 53-65.

50. Moro Visconti, R. and D. Morea, Big Data for the Sustainability of Healthcare Project Financing. Sustainability, 2019. 11(13).

51. Samir, T., et al., Big Data Research on the Green Internet of Things in New Smart-Logistics. International Journal of Innovative Technology and Exploring Engineering, 2019. 8(9S2): p. 534-537.

52. Jiao, Z., et al., Data-driven approaches to integrated closed-loop sustainable supply chain design under multi-uncertainties. Journal of Cleaner Production, 2018. 185: p. 105-127.

53. Gupta, S., et al., Circular economy and big data analytics: A stakeholder perspective. Technological Forecasting and Social Change, 2019. 144: p. 466474.

54. Badiezadeh, T., R.F. Saen, and T. Samavati, Assessing sustainability of supply chains by double frontier network DEA: A big data approach. Computers \& Operations Research, 2018. 98: p. 284-290.

55. Mani, V., et al., Mitigating Supply Chain Risk via Sustainability Using Big Data Analytics: Evidence from the Manufacturing Supply Chain. Sustainability, 2017. 9(4). 